\title{
The efficacy of video-assisted thoracoscopic surgery lung biopsies in patients with interstitial lung disease: a retrospective study of 66 patients
}

Dominic Morris ${ }^{1 *}$ and Vipin Zamvar ${ }^{2}$

\begin{abstract}
Background: Diagnosing a specific type of Interstitial Lung Disease (ILD) is a challenging process and often necessitates that a Video-assisted Thoracoscopic Surgery (VATS) Lung Biopsy be performed. By analysing the proportion of patients who have their treatment changed after undergoing a VATS lung biopsy, this study aimed to determine the utility of performing this procedure in patients with ILD.

Methods: The clinical data from sixty-six patients with suspected ILD, who underwent VATS lung biopsies at the New Royal Infirmary of Edinburgh (NRIE) in the period of 16th May 2011 - 11th February 2013, were analysed retrospectively. The main outcome measures considered in this study were: $C T$ scan differential diagnoses, VATS lung biopsy histological differential diagnoses, post-VATS lung biopsy consensus diagnoses, 30-day mortality, surgical complications (minor and major), resultant changes in treatment and responses to these changes in treatment.

Results: Following VATS biopsy a definite pathological diagnosis was made in $74.2 \%$ of cases. A change in treatment was initiated in $47.2 \%$ of patients, including in $80 \%$ of patients diagnosed with Hypersensitivity Pneumonitis and $60 \%$ of patients diagnosed with sarcoidosis. A positive response to treatment was experienced in $58 \%$ of patients whom underwent a change in treatment. Only 54\% of patients who received a consensus diagnosis of UIP after VATS lung biopsy, had been given a differential diagnosis of "probable UIP" at CT scan. 15\% of patients who received a differential diagnosis of "probable UIP" at CT scan, had their diagnosis changed to Hypersensitivity Pneumonitis after lung biopsy. There was one mortality (1.5\%) in this series of patients and no other major complications. Minor complications to surgery were experienced in $28.8 \%$ of patients.

Conclusions: This study highlights the effectiveness of performing VATS lung biopsies in patients with suspected ILD. The procedure leads to a change in treatment in almost half of all patients, including in the vast majority of cases of Hypersensitivity Pneumonitis. It also prevents what would be the inappropriate over-treatment of UIP. It has been shown to be a relatively safe procedure and thus, should be performed in all patients with suspected ILD, indeterminate in type from prior CT imaging.
\end{abstract}

Keywords: Interstitial lung disease, Video-assisted thoracoscopic surgery, Definite pathological diagnosis, Change in treatment, Usual interstitial pneumonia, Hypersensitivity pneumonitis

\footnotetext{
* Correspondence: s0901205@sms.ed.ac.uk

${ }^{1}$ College of Medicine and Veterinary Medicine, University of Edinburgh, The

Chancellor's Building, 49 Little France Crescent, Edinburgh EH16 4SB, UK

Full list of author information is available at the end of the article
} 


\section{Background}

Interstitial Lung Disease (ILD) denotes a collection of heterogeneous lung diseases which all primarily affect the interstitium of the lung. ILD most commonly presents with dyspnoea or a dry cough. Systemic features, such as weight loss or fatigue, are also common at presentation. On clinical examination, the patient will often be tachypnoeic and bibasal end inspiratory fine crackles may be heard on auscultation. Clubbing of the digits and cyanosis may occasionally occur in advanced disease and patients generally exhibit a restrictive pattern on Pulmonary Function Testing.

There are reported to be more than 200 different subtypes of ILD, so achieving a correct specific diagnosis is often challenging in a patient with ILD. This is of vital importance though, because the subtypes of ILD have different management protocols.

Computerised Tomography (CT) scanning is more specific than chest radiography in diagnosing subtypes of ILD [1]. One study reported CT scanning to carry a diagnostic accuracy of $61-80 \%$ [2]. Indeed, a CT scan which is highly typical of a particular type of ILD, may provide a physician with sufficient confidence to make the diagnosis without further investigation. For example, the presence of centrilobular nodules is highly typical of chronic Hypersensitivity Pneumonitis (HP). Conversely, the presence of basal, subpleural, reticular opacities, which are associated with honeycombing and traction bronchiectasis, would be highly typical of Usual Interstitial Pneumonia (UIP) and would probably preclude the need for further investigation. Indeed CT scanning has a diagnostic accuracy of over $90 \%$ in making the diagnosis of UIP, if radiological features are highly suggestive of the disease [3-6]. However, the CT scans of many cases of ILD, do not display features highly typical of a particular subtype of ILD; this is indeed the case in around $50 \%$ of cases of UIP [5,6].

When a diagnosis has been not achieved by CT imaging, patients can be investigated by bronchoscopy, with Bronchoalveolar Lavages (BALs) and Transbronchial Lung Biopsies (TBLBs) being performed. However, on balance, BAL is of limited utility in the diagnostic process for ILD, other than sometimes allowing for the exclusion of malignancy [7], or infection [8]. However on occasion it can be useful in detecting rare forms of ILD [9]. The diagnosing potential of TBLB is also unspectacular for many cases of ILD. A specific diagnosis is achieved in the range $29-79 \%$ of reported cases referred for the TBLB [10-14]. There are two main reasons for this: firstly, the procedure only allows the clinician to obtain a very small specimen of tissue and secondly, biopsies can only be obtained from within the peribronchial sheath.

A specific diagnosis remains unavailable to one third of all patients with ILD even after the procedures highlighted above have been conducted [15-18]. So for this sizeable group of patients, the only option remaining is for a Surgical Lung Biopsy (SLB). However, such an operation is not without its risks to the patient; indeed SLB does carry a slight risk of mortality. In recent years Videoassisted Thoracoscopic Surgery (VATS) has replaced the older, more invasive method, of performing a minithoracotomy in these patients.

The objective of this study was to assess the benefit of performing VATS to obtain a histological diagnosis in patients with ILD, indeterminate in type on CT imaging. The benefit was measured with respect to the diagnostic ability of this procedure in obtaining a Definite Pathological Diagnosis (DPD), as well as assessing the proportion of patients who have their treatment changed as a result of VATS being performed. Close attention was also paid to the safety of this procedure.

\section{Method}

Seventy nine patients with suspected ILD, who consecutively underwent a VATS lung biopsy at the New Royal Infirmary of Edinburgh in the period between 16th May 2011 - 11th February 2013 were retrospectively analysed. Exclusion criteria included: patients whose likely diagnosis was malignancy at CT scan (5 patients) and patients whose CT scan results hadn't been uploaded onto either Trak-care system or the Picture Archiving and Communication System (PACS) used by NHS Lothian (8 patients).

All data was obtained by inspection of patients' medical records. The Lothian Regional Ethics Committee deemed that the study was a service evaluation and therefore did not require formal ethical review. The data collected included: patient demographics (age, gender etc.); presenting symptoms; differential diagnoses from CT scan; pulmonary function test (PFT) readings; pre-operative treatment; number, location and size of biopsy specimens; operative complications and length of hospital stay.

Two of the minor postoperative complications experienced in the patient cohort were "delayed wound healing" and "prolonged neuropathic pain". Delayed wound healing was defined as the failure of surgical wounds to heal within 30 days of the operation. Prolonged neuropathic pain was defined as the failure of neuropathic pain to resolve within 30 days of the operation.

The decision to refer a patient for VATS lung biopsy would be made at a Multi-Disciplinary Team (MDT) meeting. VATS was carried out under general anaesthesia and single lung ventilation. Patients were intubated with a double lumen endobronchial tube and placed in the lateral decubitus position. The standard 3-port VATS technique was used. The thoracoscope was inserted into the first port site; this was created in the seventh intercostal space, somewhere between the anterior axillary line and the mid-axillary line. The locations of the two further port sites could then be determined under video-guidance. 
Biopsies were taken using an Endopath ETS $45 \mathrm{~mm}$ endoscopic linear cutter (Ethicon Endo-surgery, Cincinnati, $\mathrm{OH}$ ). Choice of biopsy site was guided by CT imaging. The decision to take single or multiple biopsies was made by the operating thoracic surgeon. A single $32 \mathrm{~F}$ chest drain was inserted into one of the anterior port sites, with the other two port sites being closed with sutures. Biopsies were injected with formalin and immersed in a jar containing formalin, then sent to Pathology.

Further data was collected regarding: histological differential diagnoses; consensus diagnoses formulated by Respiratory Physicians; postoperative changes in treatment; time taken for the initiation of treatment change and response to change in treatment.

Response to treatment was determined by analysing changes in symptoms, PFT performance, and imaging on Chest X Ray or CT scan. In most cases, changes in these clinical measures correlated, however, deterioration in any one of these clinical measures prevented the case from being considered as a "positive response to treatment".

There were limits to the data on Trak-care system: PFT readings prior to VATS were only available for 55\% of patients; data regarding size of biopsies were only available for $71 \%$ of patients; data concerning changes in treatment were available for $80 \%$ of patients; and data regarding response to treatment were available for 12 out of the 26 patients in which a change in treatment was initiated.

\section{Results}

The characteristics of the 66 patient who underwent VATS are summarised in Table $1.53 \%$ of the cohort were female and the average age of the cohort was 59 years. The commonest symptoms on first presentation were dyspnoea (73\%) and a dry (36\%) or productive (29\%) cough. The average length of time between when a patient first presented with symptoms to when the VATS procedure took place was 16 months. The average $\mathrm{FEV}_{1}$ and $\mathrm{FVC}$ readings in patients prior to VATS were $2.11 \mathrm{~L}$ and $2.71 \mathrm{~L}$ respectively. Prior to VATS being performed, $25.8 \%$ of patients had already undergone BAL and $7.6 \%$ had undergone a TBLB, whilst steroid or immunosuppressive therapy had already been initiated or trialled in $16.7 \%$ of patients.

Characteristics of the VATS lung biopsy procedure are summarised in Table 2. More than one biopsy was taken in $42.2 \%$ of patients. The average biopsy size was $16.8 \mathrm{~cm}^{2}$. The most common sites for biopsy were: the left lower lobe (44\%), the left upper lobe (41\%) and the right lower lobe (28\%).

Complications related to the VATS lung biopsy procedure are summarised in Table 3 . There was one death (30 day mortality rate: $1.5 \%$ ) in the patient cohort. The circumstances of this death were that the patient suffered a sudden deterioration in respiratory function 10 days

\section{Table 1 Characteristics of patients}

\begin{tabular}{|c|c|}
\hline \multicolumn{2}{|l|}{ No. of patients: 66} \\
\hline \multicolumn{2}{|c|}{ Gender: Male: $\mathbf{4 7} \%$, female: $\mathbf{5 3} \%$} \\
\hline \multicolumn{2}{|l|}{ Age: $\mathbf{5 8 . 9}$} \\
\hline \multicolumn{2}{|l|}{ Presenting symptoms: } \\
\hline & Dyspneoa: $\mathbf{7 2 . 7 \%}$ \\
\hline & Dry cough: $\mathbf{3 6 . 4 \%}$ \\
\hline & $\begin{array}{l}\text { Productive cough: } \\
\mathbf{2 8 . 8} \%\end{array}$ \\
\hline & $\begin{array}{l}\text { Pleuritic chest pain: } \\
\mathbf{1 0 . 6 \%}\end{array}$ \\
\hline & Haemoptysis: $\mathbf{6 . 1 \%}$ \\
\hline & Wheeze: $\mathbf{4 . 5 \%}$ \\
\hline & $\begin{array}{l}\text { Systemic disturbance: } \\
\mathbf{1 6 . 7 \%}\end{array}$ \\
\hline & Asymptomatic: $\mathbf{4 . 5 \%}$ \\
\hline
\end{tabular}

Time between first presentation and VATS lung biopsy: $\mathbf{1 6 . 1}$ months Pre-operative pulmonary function testing:

$\mathrm{FEV}_{1}: \mathbf{2 . 1 1} \mathrm{L}$

FVC: $2.71 \mathrm{~L}$

Prior investigations:

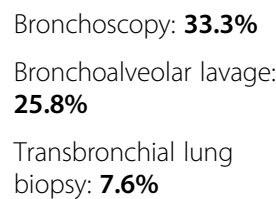

Pre-operative therapy (corticosteroid or other immunosuppressant): $\mathbf{1 6 . 7 \%}$

after surgery, thought to be secondary to sepsis, and subsequently died on postoperative day 16; autopsy revealed diffuse alveolar damage and severe interstitial pulmonary fibrosis of unclassifiable type. There were no other major complications seen in the patient cohort. Minor complications were experienced in $28.8 \%$ of patients; these included small pneumothorax (10.6\%), lower respiratory tract infection (6\%) and surgical emphysema and prolonged neuropathic pain (both 4.5\%). The average duration of time that a chest drain was left in situ was 1.15 days and the average hospital stay was 3.5 days.

\section{Table 2 Number, site and size of VATS lung biopsies}

Number $>1: \mathbf{4 2 . 2 \%}$

Biopsy volume: $16.8 \mathrm{~cm}^{2}$

Biopsy site:

Left lower lobe: $\mathbf{4 3 . 8 \%}$

Left upper lobe: $\mathbf{4 0 . 6 \%}$

Right lower lobe: $\mathbf{2 8 . 1 \%}$

Right middle lobe: $\mathbf{1 7 . 2} \%$

Right upper lobe: $\mathbf{3 . 1 \%}$ 
Table 3 Mortality and morbidity of VATS lung biopsies

30-day mortality: $\mathbf{1 . 5 \%}$

Other major complications: $\mathbf{0 \%}$

Minor complications: $\mathbf{2 8 . 8 \%}$

Small pneumothorax: $\mathbf{1 0 . 6 \%}$

LRTI: $6.1 \%$

Surgical emphysema: $\mathbf{4 . 5 \%}$

Prolonged neuropathic pain: $\mathbf{4 . 5 \%}$

Delayed wound healing: $\mathbf{3} \%$

Persistent air leak: $\mathbf{1 . 5 \%}$

Conversion to open lung biopsy: $\mathbf{0 \%}$

Chest drain duration: $\mathbf{1 . 1 5}$ days

Hospital stay: $\mathbf{3 . 5 3}$ days

The most common differential diagnoses obtained from CT scanning were UIP (in $28.8 \%$ of patients), hypersensitivity pneumonitis $(24.2 \%)$, NSIP (18.2\%), infection, Cryptogenic Organising Pneumonia, sarcoidosis and Connective Tissue Disease (all 13.6\%) (Table 4).

A Definite Pathological Diagnosis (DPD) was achieved from VATS lung biopsy in $74.2 \%$ of cases (Table 5). The most common pathological differential diagnoses made were Hypersensitivity Pneumonitis (31.8\%) and UIP (28.8\%), followed by Connective Tissue Disease (CTD) (13.6\%), NSIP (12.1\%) and sarcoidosis (10.6\%) (Table 6).

Consensus diagnoses were formulated based on findings from the CT scans and lung biopsies, in addition to consideration of the overall clinical picture of each patient. The most common consensus diagnoses made were: Hypersensitivity Pneumonitis (22.2\%), UIP (20.6\%), sarcoidosis (9.5\%) and NSIP and CTD (both 7.9\%). In 9.5\% of patients, the interstitial lung disease process occurring was deemed to be unclassifiable (Table 7).

A change in treatment was initiated in $47.2 \%$ of patients subsequent to VATS being performed. A change in treatment was initiated in: $80 \%$ of patients diagnosed

Table 4 Differential diagnoses given after CT imaging

\begin{tabular}{lcc}
\hline Ddx after CT scan & No. of patients & \% \\
\hline UIP & 19 & 28.8 \\
Hypersensitivity pneumonitis & 16 & 24.2 \\
NSIP & 12 & 18.2 \\
Infection & 9 & 13.6 \\
COP & 9 & 13.6 \\
Sarcoidosis & 9 & 13.6 \\
CTD & 9 & 13.6 \\
Malignancy & 8 & 12.1 \\
No differential given & 6 & 9.1 \\
Drug & 4 & 6.1 \\
Other & 22 & 33.3 \\
\hline
\end{tabular}

Table 5 Diagnostic accuracy of VATS lung biopsy and postoperative rates of therapy change

\section{Definite Pathological Diagnosis (DPD):}

$74.2 \%$

Change in treatment (overall): $\mathbf{4 7 . 2 \%}$

Change in treatment in "DPD" cohort: $46.2 \%$

Change in treatment in "no DPD"

cohort: $\mathbf{5 0 \%}$

Change in treatment in diagnoses of:

Hypersensitivity Pneumonitis: $\mathbf{8 0 \%}$

Sarcoidosis: $\mathbf{6 0 \%}$

NSIP: $\mathbf{4 0 \%}$

UIP: $\mathbf{9 \%}$

Positive response to treatment: $\mathbf{5 8 . 3 \%}$

Time taken for change of treatment: 12.7 weeks

with Hypersensitivity Pneumonitis; 60\% of patients with sarcoidosis and $10 \%$ of patients with UIP (Table 5). A change in treatment was initiated in $46.2 \%$ of the patients who received a DPD and $50 \%$ of the patients who did not receive a DPD (Table 5). Therapy change was initiated on average 12.7 weeks after the VATS biopsy (Table 5). Among the patients who underwent a change in treatment, $58.3 \%$ demonstrated a positive response to treatment (Table 5).

The differential diagnosis of "probable UIP" was reported in the CT scans of 13 patients. Only $54 \%$ of these patients received an eventual diagnosis of UIP, with $15 \%$ of them each having HP and NSIP (Table 8, Figure 1). $83 \%$ of patients considered to have probable $\mathrm{HP}$ at CT scan were eventually given a consensus diagnosis of HP. $33 \%$ of patients considered to have probable NSIP at $\mathrm{CT}$ scan were eventually given a consensus diagnosis of NSIP (Table 8).

Table 6 Differential diagnoses given based on VATS biopsies

\begin{tabular}{lcc}
\hline Ddx of VATS biopsy & No. of patients & $\%$ \\
\hline Hypersensitivity pneumonitis & 21 & 31.8 \\
UIP & 19 & 28.8 \\
CTD & 9 & 13.6 \\
NSIP & 8 & 12.1 \\
Sarcoidosis & 7 & 10.6 \\
Aspiration & 3 & 4.6 \\
Pulmonary Langerhans Histiocytosis & 3 & 4.6 \\
Infection & 3 & 4.6 \\
Stoneworkers pneumoconiosis & 2 & 3.0 \\
End stage fibrosis & 2 & 3.0 \\
Other & 21 & 31.8 \\
\hline
\end{tabular}


Table 7 Consensus diagnoses given after VATS biopsies

\begin{tabular}{lcc}
\hline Consensus diagnoses after VATS biopsy & No. of patients & $\%$ \\
\hline Hypersensitivity pneumonitis & 14 & 22.2 \\
UIP & 13 & 20.6 \\
Unclassifiable & 6 & 9.5 \\
Sarcoidosis & 6 & 9.5 \\
NSIP & 5 & 7.9 \\
CTD & 5 & 7.9 \\
RBILD & 3 & 4.8 \\
COP & 2 & 3.2 \\
End stage fibrosis & 2 & 3.2 \\
Vasculitis & 2 & 3.2 \\
Other & 14 & 22.2 \\
\hline
\end{tabular}

$54 \%$ of patients given a consensus diagnosis of UIP, were considered as having "probable UIP" at CT scan (Table 9). $40 \%$ of patients given a consensus diagnosis of NSIP, and $14 \%$ of patients given a consensus diagnosis of HP were considered as having "probable UIP” at CT scan (Table 9).

\section{Discussion}

Obtaining a specific diagnosis is a challenging process for many patients with ILD. CT scanning achieves a correct diagnosis in only $61-80 \%$ of cases of ILD [2], whilst the minimally invasive procedures, BAL and TBLB, have limited value in this diagnostic setting. Hence almost one third of patients with ILD will eventually require a Surgical Lung Biopsy (SLB) to obtain a definite diagnosis, with the procedure of choice in today's surgical setting being Video-Assisted Thoracoscopic Surgery (VATS) [15-18].

Prior to VATS being performed, only $7.6 \%$ of patients in this study had undergone a Transbronchial Lung Biopsy (TBLB); this figure is comparable to that (11.9\%) reported in a similar study by Qureshi et al. [19]. These figures reflect that for many cases of ILD, indeterminate in type after CT imaging, obtaining a TBLB is deemed to be unsuitable, in that the procedure is unlikely to yield a
Definite Pathological Diagnosis (DPD); such cases are instead directly referred for a Surgical Lung Biopsy (SLB). TBLBs are only likely to yield specific diagnoses in cases whereby small specimens are expected to be diagnostic, and particularly in forms of ILD with bronchocentric involvement [20]. For instance, a much larger size of specimen than that obtained by a TBLB, is normally required to make the diagnosis of UIP [21,22].

Amongst our group of 66 patients, there was only one death as a result of the VATS procedure (30 day mortality rate: $1.5 \%)$. In fact, this was the only major complication encountered in the patient cohort. Other studies have reported similar low mortality rates for VATS $(0 \%-$ $3.17 \%$ ), when performed to obtain a diagnosis of ILD [19,23-26]. There have been studies which have reported higher mortality rates for a Surgical Lung Biopsy (SLB) being performed in this setting $(4.8-24 \%)$, but all such studies have had relatively higher proportions of their patients undergoing Open Lung Biopsies (OLBs), a more invasive surgical procedure than VATS [27-30]. Minor post-operative complications were experienced in nineteen of our patients (28.8\%), a figure which is higher than that reported in other studies. Kreider et al. reported an overall post-operative complication rate of $19.1 \%$ [25], whilst the minor post-operative complication rate was only $6.8 \%$ in the study by Blackhall et al. [27]. The vast majority of the nineteen patients who experienced minor post-operative complications in this study, did not have their stay in hospital prolonged as a result, and indeed the average hospital stay reported in our study was only 3.53 days. Therefore, on balance, the complete absence of any major post-operative complications (including mortality) in sixty five out of the sixty-six patients included in the study, gives us considerable reassurance about the relative safety of the VATS procedure in this setting.

Patients included in this study had been highly selected for: they all had forms of ILD which couldn't be diagnosed on CT scan. In consideration of this fact, we would deem the diagnostic capabilities demonstrated by

Table 8 Correlation between CT scan differential diagnoses and post-VATS biopsy consensus diagnoses

\begin{tabular}{|c|c|c|c|c|c|c|c|c|}
\hline \multirow{2}{*}{$\begin{array}{l}\text { CT differential } \\
\text { Diagnosis }\end{array}$} & \multirow{2}{*}{$\begin{array}{l}\text { Level of } \\
\text { certainty }\end{array}$} & \multirow{2}{*}{$\begin{array}{l}\text { No. of } \\
\text { cases }\end{array}$} & \multicolumn{5}{|c|}{ Consensus diagnosis (after VATS biopsy) } & \multirow{2}{*}{$\begin{array}{l}\text { Correct } \\
\text { diagnosis }\end{array}$} \\
\hline & & & UIP & HP & NSIP & Sarcoidosis & Other & \\
\hline UIP & Probable & 13 & 7 & 2 & 2 & 1 & 1 & $54 \%$ \\
\hline UIP & Possible & 6 & 3 & 1 & 1 & 0 & 1 & $50 \%$ \\
\hline $\mathrm{HP}$ & Probable & 6 & 0 & 5 & 0 & 0 & 1 & $83 \%$ \\
\hline $\mathrm{HP}$ & Possible & 9 & 5 & 2 & 0 & 2 & 0 & $22 \%$ \\
\hline NSIP & Probable & 3 & 0 & 0 & 1 & 0 & 2 & $33 \%$ \\
\hline NSIP & Possible & 9 & 4 & 2 & 2 & 0 & 1 & $22 \%$ \\
\hline Sarcoidosis & Probable & 3 & 0 & 0 & 0 & 2 & 1 & $67 \%$ \\
\hline Sarcoidosis & Possible & 6 & 0 & 0 & 0 & 3 & 3 & $50 \%$ \\
\hline
\end{tabular}




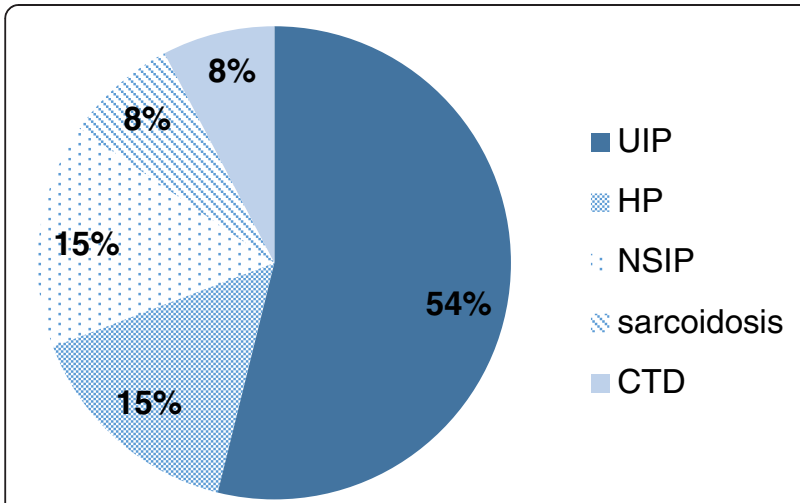

Figure 1 Proportional breakdown of postoperative consensus diagnoses given to CT differential diagnoses of "probable UIP".

VATS in our study - in obtaining a DPD in around three quarters of cases - to be substantial. There is marked variation between what previous studies have reported the rate of DPDs being yielded by SLBs to be; figures vary between $34-100 \%$ [24,26,27,31-33]. A figure comparable to this study $(69.9 \%)$ was recently reported by Blackhall et al. [27], whilst two other studies reported a DPD being obtained from $100 \%$ of the patients with suspected ILD, undergoing the VATS procedure $[24,26]$. It is worth noting, our data did not show there to be a reduced rate of therapy change among the $25.8 \%$ of patients with no DPD after VATS. This may indicate that even when VATS fails to provide a DPD, it can still be of great help to the clinician, in excluding various differential diagnoses proposed by prior $\mathrm{CT}$ imaging, and thus narrowing the diagnostic possibilities for a patient.

That VATS biopsy provoked a change in treatment in almost half of our patients gives strong suggestion that this procedure is of considerable benefit to patients with ILD. Other studies have reported similar numbers of patients having their therapy altered after SLB. In a recent study by Blackhall et al., $45.6 \%$ of patients had their therapy altered [27], whilst Kramer et al. reported a change in therapy in $46 \%$ of its patients after SLB [34]. Fifty four per cent of patients with ILD had their therapy altered after SLB, in a report by Walker et al. [32]. An even higher percentage of patients received a change in therapy (84.2\%) in their report of 196 patients by Lee et al. [30].

Our data also demonstrates there to be a clinical benefit for the majority of patients who have undergone a change in therapy after VATS: $58 \%$ of our patients demonstrated a positive response to treatment. A similar proportion of patients (63.3\%) were shown to display a clinical improvement after SLB in the study by Lee et al. too [30].

However, it was not just by provoking an initiation of new treatment that long term management of these patients was aided by obtaining a VATS lung biopsy. We would also argue that VATS biopsy was of benefit to patients receiving a UIP diagnosis. UIP was the second commonest consensus diagnosis made amongst our patients. The progression of UIP has been shown to be unaffected by pharmacological intervention, and thus NICE currently does not recommend pharmacological intervention for most cases of UIP; the guidelines state: "there is no conclusive evidence to support the use of any drugs to increase survival of people with IPF" [35]. A change in treatment was initiated in only $9 \%$ of our patients diagnosed with UIP. Thus steroid therapy was withheld in the overwhelming majority of our patients who received a diagnosis of UIP. Crucially, only $54 \%$ of patients receiving a diagnosis of UIP after undergoing a VATS lung biopsy had originally been given a diagnosis of "probable UIP" at CT scan (Table 9). The VATS lung biopsy particularly served to benefit the remaining $46 \%$ of patients whose CT scans had not indicated "probable UIP": if these patients had not undergone VATS lung biopsies, they may have ended up with alternative ILD diagnoses and as a result, been unnecessarily exposed to the toxic side effects of immunosuppressive therapy.

Whilst UIP was the most frequent differential diagnosis made at CT scan among our patients, it was only the second most common differential reported at VATS biopsy, and likewise the second most common disease assigned as a consensus diagnosis. Hypersensitivity Pneumonitis instead, became the foremost ILD type diagnosed in our patient cohort after VATS (Table 7). Hypersensitivity Pneumonitis, in contrast to UIP, is a form of ILD which does respond to steroid therapy [20]. Indeed steroid therapy

Table 9 Correlation between CT scan differential diagnoses and post-VATS biopsy consensus diagnoses

\begin{tabular}{|c|c|c|c|c|c|c|c|c|}
\hline \multirow{2}{*}{$\begin{array}{l}\text { Consensus diagnosis } \\
\text { (after VATS biopsy) }\end{array}$} & \multirow{2}{*}{$\begin{array}{l}\text { No. of } \\
\text { cases }\end{array}$} & \multicolumn{7}{|c|}{ Probable diagnosis at CT scan } \\
\hline & & UIP & HP & NSIP & Sarcoidosis & Malignancy & Other & Ambiguous \\
\hline UIP & 13 & $7(54 \%)$ & 0 & 0 & 0 & 0 & 2 & 4 \\
\hline $\mathrm{HP}$ & 14 & $2(14 \%)$ & $5(36 \%)$ & 0 & 0 & 0 & 2 & 5 \\
\hline Sarcoidosis & 6 & $1(17 \%)$ & 0 & 0 & $2(33 \%)$ & 0 & 0 & 3 \\
\hline NSIP & 5 & $2(40 \%)$ & 0 & $1(20 \%)$ & 0 & $1(20 \%)$ & 1 & 0 \\
\hline Malignancy & 1 & 0 & 0 & 0 & 0 & 0 & 1 & 0 \\
\hline
\end{tabular}

Proportional breakdown of preoperative "probable diagnoses at CT scan" given to consensus diagnoses of UIP, Hypersensitivity Pneumonitis (HP), sarcoidosis, NSIP and malignancy. 
was initiated in $80 \%$ of our HP patients post-VATS biopsy; this figure would have been even higher if it wasn't for the fact that steroid therapy was contraindicated in one particular patient with osteoporosis.

Our data shows VATS biopsy to be useful in that it frequently manages to differentiate HP from UIP: $15 \%$ of CT cases which were considered as "probable UIP" on CT scan, were proven to be HP on histology (Table 8, Figure 1). Moreover, $14 \%$ of the cases of biopsy-proven HP had earlier been considered as "probable UIP" on CT scan (Table 9). There are certain radiological features which are particularly specific to HP (centrilobular nodules) or UIP (basal, subpleural, reticular opacities associated with traction bronchiectasis) and allow for their confident differentiation on CT scan. However, when these disease-specific radiological features are absent, and when radiological patterns common to both HP and UIP (honeycombing, ground glass attenuation) predominate on CT scan, it is difficult to distinguish between these two diseases with a high level of confidence. Lynch et al. found that the accuracy of distinguishing UIP from HP on CT scan falls from 90\%, when the CT diagnosis is made with a high level of confidence, to $60 \%$, when the features on CT scan don't allow a high level of confidence [36]. Silva et al. reported that UIP can be confidently distinguished from HP (or NSIP) by CT imaging in only $53 \%$ of cases [37]. In a more recent study by Sverzellati et al., thoracic radiologists retrospectively reviewed the CT scans of 55 patients with biopsyproven UIP; a probable diagnosis of HP was made in $7 \%$ of these CT scans [38].

Non-Specific Interstitial Pneumonia (NSIP) is another variant of ILD which can often be difficult to distinguish from UIP on CT scan alone, and this was also shown in our data: $40 \%$ of the cases of biopsy-proven NSIP, had been considered as "probable UIP" on CT scan (Table 9). One study demonstrated an incorrect diagnosis of probable NSIP to be retrospectively made in $34 \%$ of patients with biopsy-proven UIP [3]. In a retrospective study of 55 patients with biopsy-proven UIP, by Sverzellati et al., $33 \%$ of CT scans retrospectively analysed, were classed as probable NSIP [38]. Again, the clinical implications of being able to accurately distinguish NSIP from UIP are considerable: NSIP, as well as having a substantially better prognosis than UIP, is also a disease which is much more likely to be responsive to immunosuppressive therapy. Indeed steroid therapy was initiated in $40 \%$ of the patients who were given a consensus diagnosis of NSIP in our study.

\section{Conclusion}

It is beneficial to obtain a VATS lung biopsy in patients with ILD indeterminate in type from prior investigation. With the deployment of this procedure, a specific diagnosis can be obtained in roughly three quarters of these patients, with a resultant change in treatment being prompted in almost half of these patients, including in the vast majority of Hypersensitivity Pneumonitis cases. It also ensures that patients with UIP aren't given inappropriate immunosuppressive treatment. It is recommended that the VATS procedure is performed for all patients with ILD indeterminate in type from prior investigation.

\section{Competing interests}

The authors declare that they have no competing interests.

\section{Authors' contributions}

DM participated in the design of the study and drafted the manuscript. VZ conceived of the study, and participated in its design. Both authors read and approved of the final manuscript.

\section{Acknowledgements}

We acknowledge the work of the cardiothoracic surgery team at the New Royal Infirmary of Edinburgh.

\section{Author details}

${ }^{1}$ College of Medicine and Veterinary Medicine, University of Edinburgh, The Chancellor's Building, 49 Little France Crescent, Edinburgh EH16 4SB, UK. ${ }^{2}$ Department of Cardio-thoracic Surgery, New Royal Infirmary of Edinburgh, 51 Little France Crescent, Edinburgh EH16 4SA, UK.

Received: 18 December 2013 Accepted: 28 February 2014 Published: 10 March 2014

\section{References}

1. Mathieson JR, Mayo JR, Staples CA, Müller NL: Chronic diffuse infiltrative lung disease: comparison of diagnostic accuracy of $\mathrm{CT}$ and chest radiography. Radiology 1989, 171:111-116.

2. Grenier P, Chevret S, Beigelman C, Brauner MW, Chastang C, Valeyre D: Chronic diffuse infiltrative lung disease: determination of the diagnostic value of clinical data, chest radiography, and CT and Bayesian analysis. Radiology 1994, 191:383-390.

3. Flaherty KR, Thwaite EL, Kazerooni EA, Gross BH, Toews GB, Colby TV, Travis WD, Mumford JA, Murray S, Flint A, Lynch JP 3rd, Martinez FJ: Radiological versus histological diagnosis in UIP and NSIP: survival implications. Thorax 2003, 58:143-148.

4. Flaherty KR, King TE Jr, Raghu G, Lynch JP 3rd, Colby TV, Travis WD, Gross BH, Kazerooni EA, Toews GB, Long Q, Murray S, Lama VN, Gay SE, Martinez FJ: Idiopathic interstitial pneumonia: what is the effect of a multidisciplinary approach to diagnosis? Am J Respir Crit Care Med 2004, 170:904-910.

5. Hunninghake GW, Zimmerman MB, Schwartz DA, King TE Jr, Lynch J, Hegele R, Waldron J, Colby T, Müller N, Lynch D, Galvin J, Gross B, Hogg J, Toews G, Helmers R, Cooper JA Jr, Baughman R, Strange C, Millard M: Utility of a lung biopsy for the diagnosis of idiopathic pulmonary fibrosis. Am J Respir Crit Care Med 2001, 164:193-196.

6. Raghu G, Mageto YN, Lockhart D, Schmidt RA, Wood DE, Godwin JD: The accuracy of the clinical diagnosis of new-onset idiopathic pulmonary fibrosis and other interstitial lung disease: A prospective study. Chest 1999, 116:1168-1174.

7. Betsuyaku T, Munakata M, Yamaguchi E, Ohe S, Hizawa N, Sukoh N, Yamashiro K, Mikuni C, Kawakami Y: Establishing diagnosis of pulmonary malignant lymphoma by gene rearrangement analysis of lymphocytes in bronchoalveolar lavage fluid. Am J Respir Crit Care Med 1994, 149:526-529.

8. Baughman RP: Use of bronchoscopy in the diagnosis of infection in the immunocompromised host. Thorax 1994, 49:3-7.

9. Martin RJ, Coalson JJ, Rogers RM, Horton FO, Manous LE: Pulmonary alveolar proteinosis: the diagnosis by segmental lavage. Am Rev Respir Dis 1980, 121:819-825.

10. Zavala DC: Diagnostic fiberoptic bronchoscopy: Techniques and results of biopsy in 600 patients. Chest 1975, 68:12-19.

11. Mitchell DM, Emerson CJ, Collins JV, Stableforth DE: Transbronchial lung biopsy with the fibreoptic bronchoscope: analysis of results in 433 patients. Br J Dis Chest 1981, 75:258-262. 
12. Haponik EF, Summer WR, Terry PB, Wang KP: Clinical decision making with transbronchial lung biopsies. The value of nonspecific histologic examination. Am Rev Respir Dis 1982, 125:524-529.

13. Wall CP, Gaensler EA, Carrington CB, Hayes JA: Comparison of transbronchial and open biopsies in chronic infiltrative lung diseases. Am Rev Respir Dis 1981, 123:280-285.

14. Poletti V, Patelli M, Ferracini R, Simonetti M, Spiga L: Transbronchial lung biopsy in infiltrative lung disease. The importance of the pathologic approach. Sarcoidosis 1988, 5:43-50.

15. Schmidt SL, Sundaram B, Flaherty KR: Diagnosing fibrotic lung disease: when is high-resolution computed tomography sufficient to make a diagnosis of idiopathic pulmonary fibrosis? Respirology 2009, 14:934-939.

16. Jara-Palomares L, Martín-Juan J, Gómez-lzquierdo L, Cayuela-Domínguez A Rodríguez-Becerra E, Rodríguez-Panadero F: Bronchoalveolar lavage findings in patients with diffuse interstitial lung disease: prospective study of a cohort of 562 patients. Arch Bronconeumol 2009, 45:111-117.

17. Shim HS, Park MS, Park IK: Histopathologic findings of transbronchial biopsy in usual interstitial pneumonia. Pathol Int 2010, 60:373-377.

18. Gaensler EA, Carrington CB: Open biopsy for chronic diffuse infiltrative lung disease: clinical, roentgenographic, and physiological correlations in 502 patients. Ann Thorac Surg 1980, 30:411-426.

19. Qureshi RA, Soorae AA: Efficacy of thoracoscopic lung biopsy in interstitial lung diseases: comparison with open lung biopsy. J Coll Physicians Surg Pak 2003, 13:600-603.

20. Bradley B, Branley HM, Egan JJ, Greaves MS, Hansell DM, Harrison NK, Hirani N, Hubbard R, Lake F, Millar AB, Wallace WA, Wells AU, Whyte MK, Wilsher ML, British Thoracic Society Interstitial Lung Disease Guideline Group, British Thoracic Society Standards of Care Committee; Thoracic Society of Australia; New Zealand Thoracic Society; Irish Thoracic Society: Interstitial lung disease guideline: the British thoracic society in collaboration with the thoracic society of Australia and New Zealand and the Irish thoracic society. Thorax 2008, 63(Suppl 5):1-58.

21. Berbescu EA, Katzenstein AL, Snow JL, Zisman DA: Transbronchial biopsy in usual interstitial pneumonia. Chest 2006, 129:1126-1131.

22. Gal AA: Use and abuse of lung biopsy. Adv Anat Pathol 2005, 12:195-202.

23. Ayed AK, Raghunathan R: Thoracoscopy versus open lung biopsy in the diagnosis of interstitial lung disease: a randomised controlled trial. J R Coll Surg Edinb 2000, 45:159-163.

24. Rena O, Casadio C, Leo F, Giobbe R, Cianci R, Baldi S, Rapellino M, Maggi G: Videothoracoscopic lung biopsy in the diagnosis of interstitial lung disease. Eur J Cardiothorac Surg 1999, 16:624-627.

25. Kreider ME, Hansen-Flaschen J, Ahmad NN, Rossman MD, Kaiser LR, Kucharczuk JC, Shrager JB: Complications of video-assisted thoracoscopic lung biopsy in patients with interstitial lung disease. Ann Thorac Surg 2007, 83:1140-1144

26. Luo Q, Han Q, Chen X, Xie J, Wu L, Chen R: The diagnosis efficacy and safety of video-assisted thoracoscopy surgery (VATS) in undefined interstitial lung diseases: a retrospective study. J Thorac Dis 2013, 5:283-288.

27. Blackhall V, Asif M, Renieri A, Civitelli S, Kirk A, Jilaihawi A, Granato F: The role of surgical lung biopsy in the management of interstitial lung disease: experience from a single institution in the UK. Interact CardiovasC Thorac Surg 2013, 17:253-257.

28. LoCicero J 3rd: Does every patient with enigmatic lung disease deserve a lung biopsy? The continuing dilemma. Chest 1994, 106:706-708.

29. Lettieri CJ, Veerappan GR, Helman DL, Mulligan CR, Shorr AF: Outcomes and safety of surgical lung biopsy for interstitial lung disease. Chest 2005, 127:1600-1605.

30. Lee YC, Wu CT, Hsu HH, Huang PM, Chang YL: Surgical lung biopsy for diffuse pulmonary disease: experience of 196 patients. J Thorac Cardiovasc Surg 2005, 129:984-990.

31. Sigurdsson MI, Isaksson HJ, Gudmundsson G, Gudbjartsson T: Diagnostic surgical lung biopsies for suspected interstitial lung diseases: a retrospective study. Ann Thorac Surg 2009, 88:227-232.

32. Walker WA, Cole FH Jr, Khandekar A, Mahfood SS, Watson DC: Does open lung biopsy affect treatment in patients with diffuse pulmonary infiltrates? J Thorac Cardiovasc Surg 1989, 97:534-540.

33. Qureshi RA, Ahmed TA, Grayson AD, Soorae AS, Drakeley MJ, Page RD: Does lung biopsy help patients with interstitial lung disease? Eur J Cardiothorac surg 2002, 21:621-626.
34. Kramer MR, Berkman N, Mintz B, Godfrey S, Saute M, Amir G: The role of open lung biopsy in the management and outcome of patients with diffuse lung disease. Ann Thorac Surg 1998, 65:198-202.

35. National Institute for Health and Care Excellence: The diagnosis and management of suspected idiopathic pulmonary fibrosis]. [CG163]. London: National Institute for Health and Care Excellence; 2013.

36. Lynch DA, Newell JD, Logan PM, King TE Jr, Müller NL: Can CT distinguish hypersensitivity pneumonitis from idiopathic pulmonary fibrosis? AJR Am J Roentgenol 1995, 165:807-811.

37. Silva Cl, Müller NL, Lynch DA, Curran-Everett D, Brown KK, Lee KS, Chung MP, Churg A: Chronic hypersensitivity pneumonitis: differentiation from idiopathic pulmonary fibrosis and nonspecific interstitial pneumonia by using thin-section CT. Radiology 2008, 246:288-297.

38. Sverzellati N, Wells AU, Tomassetti S, Desai SR, Copley SJ, Aziz ZA, Zompatori M, Chilosi M, Nicholson AG, Poletti V, Hansell DM: Biopsy-proved idiopathic pulmonary fibrosis: spectrum of nondiagnostic thin-section CT diagnoses. Radiology 2010, 254:957-964.

doi:10.1186/1749-8090-9-45

Cite this article as: Morris and Zamvar: The efficacy of video-assisted thoracoscopic surgery lung biopsies in patients with interstitial lung disease: a retrospective study of 66 patients. Journal of Cardiothoracic Surgery 2014 9:45.

\section{Submit your next manuscript to BioMed Central and take full advantage of:}

- Convenient online submission

- Thorough peer review

- No space constraints or color figure charges

- Immediate publication on acceptance

- Inclusion in PubMed, CAS, Scopus and Google Scholar

- Research which is freely available for redistribution 